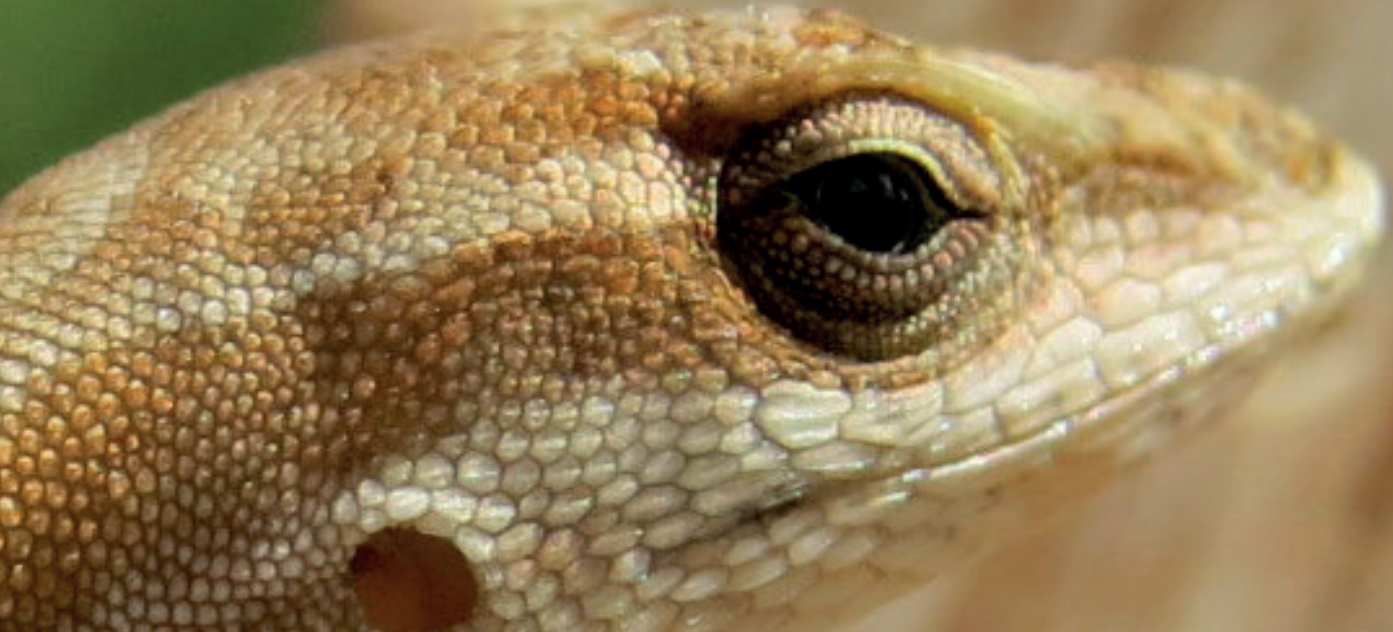

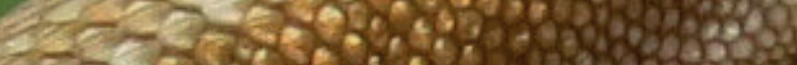
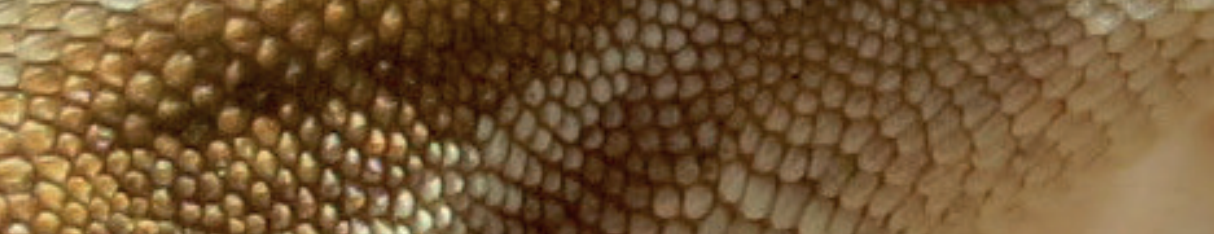

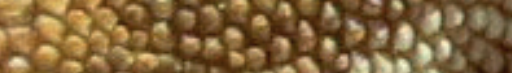

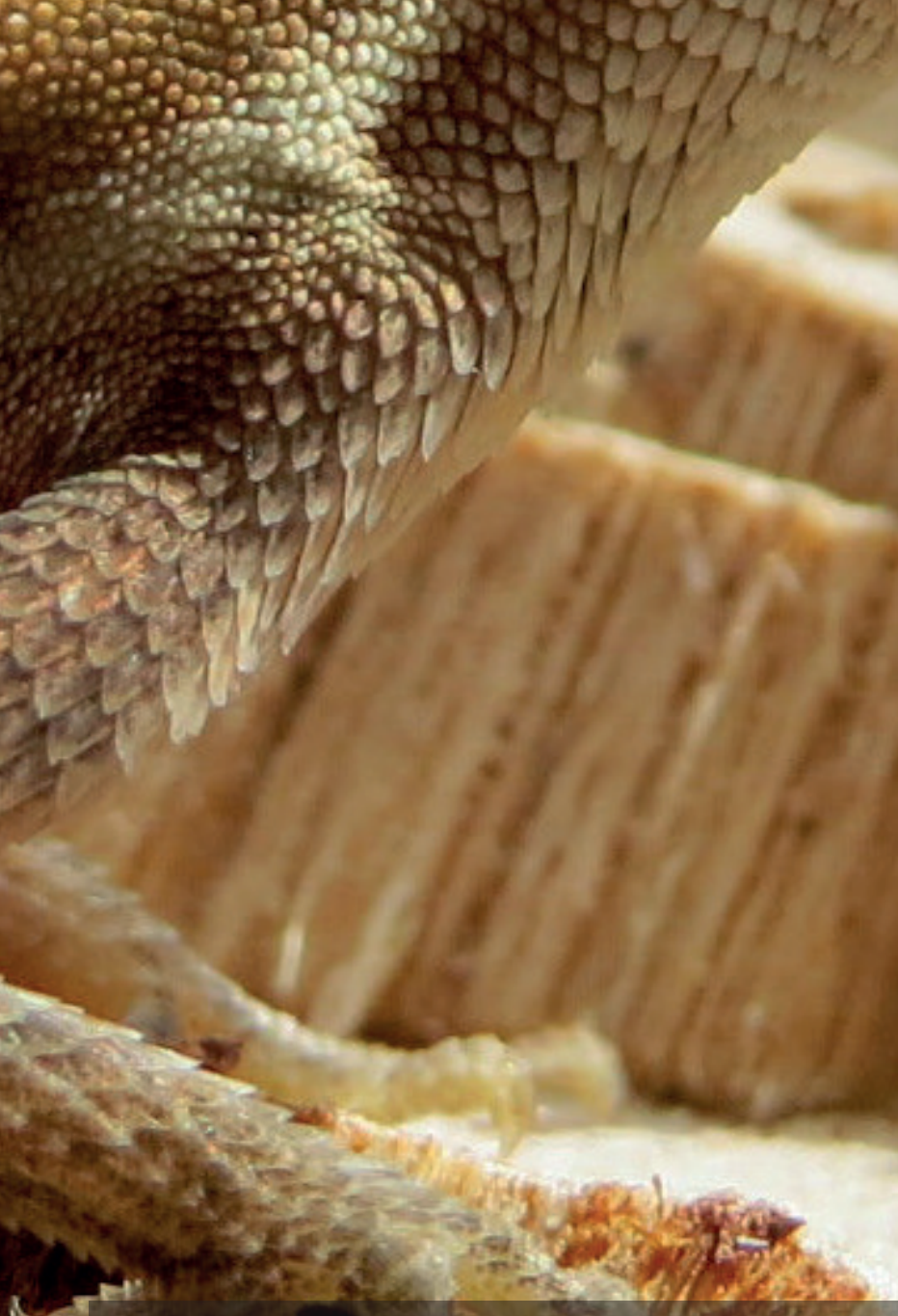

Fotografía: Anolis sp

Erik Camilo Gaitan Lopez

Licenciado en Ciencias Naturales: Física, Quimica y Biología de la Universidad Surcolombiana.
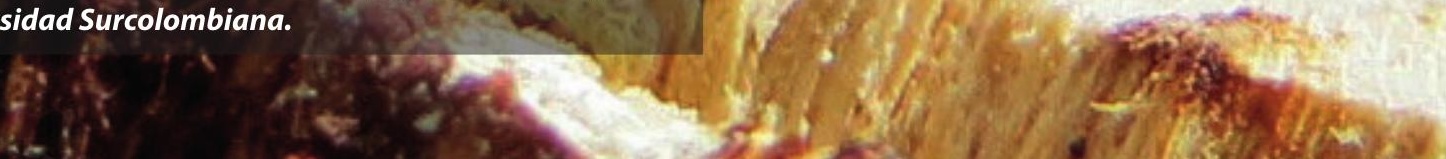


\title{
CARTILLA PARA DOCENTES DEL INSTITUTO PEDAGÓGICO NACIONAL SOBRE SIMBIOSISY PROCESOS BIOTECNOLÓGICOS: EL BIOFERTILIZANTE RHIZOBIUM SP COMO ALTERNATIVA PARA LA SIMBIOSIS CON PHASEOLUS VULGARIS \\ BOOKLET TO INSTITUTO PEDAGOGICO NACIONAL TEACHERS ABOUT SYMBIOSIS AND PROCESSES ON BIOTECHNOLOGY: THE BIOFERTILIZER Rhizobium sp IN Phaseolus vulgaris WITH ALTERNATIVE TO SYMBIOSIS FOR Phaseolus vulgaris
}

Fecha de recepción: 13 de agosto de 2014

Fecha de aprobación: 01 de abril de 2015

\author{
María Camila Quevedo Rubiano ${ }^{1}$
}

\section{Resumen}

Este artículo presenta los resultados del trabajo de grado desarrollado en la línea de investigación "Enseñanza de la biotecnología en Colombia", con el objetivo de aportar a los docentes de Biología del Instituto Pedagógico Nacional una cartilla que puede fortalecer la enseñanza de los procesos biotecnológicos con el uso de Rhizobium sp para la reducción de fertilizantes químicos y la simbiosis con Phaseolus vulgaris.

La cartilla contiene una propuesta de actividades prácticas que le permiten a los docentes de esta institución hacer uso de espacios como la granja, propicios para enseñar la biotecnología relacionada con la agronomía. Por lo tanto, para desarrollar este trabajo se tuvo en cuenta dos enfoques: biológico y pedagógico. El primero se encuentra dentro del paradigma empírico-analítico en el proceso de caracterización microbiológica de Rhizobium y su capacidad biofertilizante en el frijol; y el pedagógico con el diseño de la cartilla que incluye los hallazgos de este trabajo como un aporte para la reducción de fertilizantes químicos de la granja escolar. Con el fin de tener un análisis completo, este trabajo fue sometido a la modalidad cuantitativa y cualitativa.

En la cartilla se incluye esta práctica biotecnológica, mostrando que en los bioensayos las bacterias tienen potencial biofertilizante sin inhibir la simbiosis, y que puede promoverse en la clase de Biología la investigación, la enseñanza de conceptos biológicos a partir de competencias científicas para que de forma significativa el estudiante comprenda su contexto, se emplee en diferentes niveles de enseñanza; además, cumple como estrategia didáctica.

\section{Palabras claves:}

Cartilla; Rhizobium sp; Phaseolus vulgaris; biofertilizante; Enfoque Ciencia; Tecnología; Sociedad y Ambiente (CTSA)

1 Licenciada en Biología de la Universidad Pedagógica Nacional, Bogotá, Colombia.

Correo electrónico: mc.quevedo90@hotmail.com, dbi.mquevedo@pedagogica.edu.co 


\section{Abstract:}

This article presents the results of the thesis carried out in the research group of Biotechnology Teaching in Colombia, with the aim of providing teachers of Biology of Instituto Pedagogico Nacional a booklet that can strengthen the teaching of biotechnology processes using Rhizobium $\mathrm{sp}$ reduction of chemical fertilizers and symbiosis with Phaseolus vulgaris.

The booklet contains a proposal of practical activities that enable teachers of this institution to use spaces like the farm, enabling to teach biotechnology related to agronomy. Therefore, for this project was considered two Biological and Pedagogical approaches, the first is within the analytical empirical paradigm in the process of microbiological characterization of Rhizobium and their Biofertilizing ability in beans; and the teaching approach within the design of a booklet that includes the findings of this study as a contribution to the reduction of chemical fertilizers school farm. In order to have a complete analysis of the work it was subjected to quantitative and qualitative methods.

This biotech practice is included in the booklet showing in bioassays that bacteria has biofertilizer without inhibiting potential symbiosis, and that research and teaching biological concepts from scientific expertise can be promoted in Biology class for students to understand its context in a significant way, to be used in different levels of education; also it is a teaching strategy.

\section{Key Words:}

Booklet; Rhizobium sp; Phaseolus vulgaris; Biofertilizer; Approach Science; Technology; Society and Environmental (CTSA)

\section{Introducción}

A la realidad de los suelos ácidos en Latinoamérica, donde se desarrolla la planta del frijol Phaseolus vulgaris, se suman la acelerada producción agrícola a partir de estrategias para aumentar los ingresos de los agricultores y mantener la alimentación mundial, empleando el uso de fertilizantes químicos sin tener en cuenta el daño ecológico generado al suelo, su productividad, contaminación de fuentes hídricas y problemas de salud (Rivera, 2012). El uso de productos externos para nivelar las concentraciones de fósforo, potasio y nitrógeno (PKN) se hace necesario para cultivar el frijol en suelo con carencia de nitrógeno.
Una alternativa de solución se encuentra en imitar las estructuras de los sistemas biológicos, específicamente en la relación simbiótica entre Phaseolus vulgaris y Rhizobium sp, este es un microorganismo fijador de nitrógeno que contribuye con la mayor cantidad de este elemento fijado en especies agrícolas (Peoples et al., 1995; Chianu et al., 2010; citados en Rivera, 2012); reduciendo costos de producción externa y el equilibrio a los agroecosistemas. Esta situación muestra que la biotecnología y agronomía pueden trabajar en las poblaciones microbianas, sus interacciones y beneficios, para contrarrestar productos de síntesis química que, en altas concentraciones de nitrato y amonio, inhiben la formación de nódulos de las plantas donde ocurre la fijación biológica del nitrógeno (FBN) en el frijol. Además, los cultivos son más propensos al ataque de plagas o pueden acrecentarse efectos biológicos de la acidez de los suelos con el uso excesivo o repetitivo de los fertilizantes químicos (Altieri y Nicholls, 2004).

Por lo tanto, desde la biotecnología se ha trabajado con el uso de microorganismos que involucren el principio activo para estudiar el potencial biofertilizante en los suelos del cultivo del frijol, donde se ha encontrado respuestas positivas en la simbiosis Phaseolus vulgaris y Rhizobium sp, debido a que los rizobios muestran mejores rendimientos en la planta y reduce el contragolpe ecológico generado por las inadecuadas estrategias para abordar el manejo a los agroecosistemas (Nicolls y Altieri, 2004; Ben Rebah, et al., 2007; citado por Rivera, 2012).

De esta manera, la enseñanza de la biología toma un lugar importante para que el maestro reflexione acerca del papel significativo en la vida de sus estudiantes, por medio de estrategias que permitan pensar en el uso de materiales didácticos para complementar la labor de maestro con aportes tanto disciplinares y pedagógicos que hagan estas herramientas más útiles y completas (Baquero y Rojas, 2005). La cartilla que es presentada en este artículo tuvo en cuenta la experiencia de práctica en el Instituto Pedagógico Nacional (IPN) para acercar temas que permitan motivar interés por la enseñanza de la biotecnología que se vive en la institución y el trabajo práctico, debido a que en el IPN no existe una cartilla que apoye la enseñanza de la biología. En la cartilla se propone el uso de espacios de aprendizaje como el semillero de investigación, el aula de clase, salidas educativas, laboratorios, mapa geográfico, entre otros, propuestas que tienen por objeto involucrar a los estudiantes en su propio aprendizaje como sujetos activos. Este material no es el reemplazo de la enseñanza en biología, sino un complemento del trabajo práctico para este colegio, en especial como ayuda al maestro en las clases. 
Por consiguiente, se pretende incluir desde la Ciencia, Tecnología, Sociedad y Ambiente (CTSA), elementos teóricos de la relación ecológica de los rizobios y el frijol, deteriorada con el uso excesivo de los fertilizantes, ayudándoles a los estudiantes a tomar decisiones ciudadanas al dar cuenta de las causas del deterioro al suelo y estructura de la raíz del frijol con el uso de productos químicos, el contexto colombiano de los precios y la dependencia de los pequeños agricultores.

Para fomentar con esta propuesta desde el área biotecnología una formación de futuros científicos que pueden hacer uso de bacterias para la elaboración de productos de rizobios y de la experimentación, enseñándoles a interpretar fenómenos naturales al observar en la aplicación biotecnológica la simbiosis, y así actuar de manera crítica y responsable ante los problemas sociales de la ciencia (Del Carmen, 1994; citado por Quintero, 2009, p. 53). Incluso, dentro del papel del maestro en la enseñanza-aprendizaje de la biología debe ser tomada en cuenta la biotecnología que se enseña en la escuela debido a que es una disciplina que se aproxima a la naturaleza de la ciencia y las necesidades sociales (Roa, Chavarro y Sandoval, 2008) para desarrollar en los estudiantes competencias conceptuales, procedimentales y actitudinales, aportando al conocimiento de contenidos científicos relevantes (Alcaldía Mayor de Bogotá, 2007).

Durante el trabajo de grado, el objetivo principal fue diseñar una cartilla sobre el biofertilizante elaborado con la bacteria Rhizobium sp en Phaseolus vulgaris dirigido a docentes de Biología del Instituto Pedagógico Nacional (IPN), como aporte a la enseñanza de los procesos biotecnológicos y la reducción de fertilizantes químicos. Para alcanzar el objetivo, fue necesario primero partir del componente biológico haciendo uso del cepario del Departamento de Biología de la Universidad Pedagógica Nacional. En los objetivos específicos, se determinó las características morfológicas y bioquímicas de Rhizobium sp con capacidad biofertilizante del cepario de la Universidad, se estableció la diferencia entre el uso de fertilizantes químicos y biofertilizantes, se generó una cartilla sobre la aplicación del biofertilizante como aporte a la enseñanza y se validó la cartilla centrada en prácticas en la granja integral del IPN.

\section{Materiales y métodos}

En este trabajo se hace uso de la investigación mixta (cuantitativa y cualitativa) y del paradigma empírico analítico característico de la investigación cuantitativa para obtener resultados del método científico. La modalidad cualitativa para dar a conocer los hallazgos del trabajo biológico con la cartilla como estrategia didáctica dirigida a los docentes de Biología del Instituto Pedagógico Nacional. Estas dos modalidades investigativas se tienen en cuenta debido a que no es posible tener un análisis separado, ni referir a lo cuantitativo sin hablar de lo cualitativo, ya que ambas son un cuerpo inseparable (Cerda, 2002). En esta medida, la metodología se divide en fases de trabajo correspondientes a los componentes biológico y pedagógico relacionados con los objetivos de la investigación:

Fase I: Se determinaron las características morfológicas y bioquímicas de Rhizobium sp con capacidad biofertilizante del cepario de la Universidad Pedagógica Nacional, replicando 12 cepas conservadas en medio sólido y líquido inoculadas en ELMARC (extracto de levadura, manitol, agar y rojo congo); comúnmente utilizado para aislar rizobios, por la presencia del rojo congo y el manitol para la diferenciación de estas bacterias que acidifican el medio (Rivera, 2012); extracto de levadura que le proporciona a las bacterias productos de degradación de proteínas, sustratos para la respiración, vitaminas y reguladores de crecimiento (Contreras, Iriarte y Muñoz, 2007), así como aislamiento y purificación para corroborar el género con pruebas bioquímicas de SıM (sulfato, indol y movilidad), TSı (lactosa, sacarosa y glucosa), citrato, catalasa y YMA (azul de bromotimol) y de este modo determinar el género Rhizobium (Crespo y Julio, 2012).

Fase II: Se tuvo en cuenta las diferencias entre el uso de fertilizantes químicos (ver abajo) y biofertilizantes de la bacteria Rhizobium sp para promover el empleo de estos últimos en prácticas realizadas en escenarios escolares haciendo pruebas fisicoquímicas del suelo como materia orgánica, nitrógeno, humedad relativa, capacidad de intercambio catiónico, fósforo, calcio, magnesio, potasio, sodio, textura y $\mathrm{pH}$. Se realizó una esterilización del material usado para el cultivo del frijol, pregerminando las semillas en papel absorbente y arena, llevando a cabo bioensayos en un espacio hermético que no afectara la estructura de la planta y elaborando los biofertilizantes con dos formulaciones: líquida, haciendo siembra masiva en cajas de Petri de la bacteria pura y depositando la cantidad de bacterias en agua peptonada; y sólida, utilizando bolsas de polietileno con turba mezclada con medio de cultivo liquido e inoculado con la bacteria. En el montaje cada matera contenía 3 semillas pregerminadas del frijol, con un tratamiento diferente cada una y su réplica respectiva. Los tratamientos estudiados fueron:

- Tratamiento 1 control negativo: Se utiliza un fertilizante de síntesis química Crecilizer $^{\circledR}$ del ICA. En concentración de $10 \mathrm{ml} \times 1$ I de agua 
- Tratamiento 2 control neutro: Agua esterilizada.

- Tratamiento 3 control experimental: Formulación sólida a partir de turba para asegurar la cantidad de rizobios en el suelo y semilla al momento de la siembra, y formulación líquida para nutrir la planta en cada aspersión (máximo 109 uFc/ml).

- Tratamiento 4 control positivo: Biofertilizante Rhizobio $^{\circledast}$ de Corpoica $\left(1 \times 10^{9}\right.$ ufc $\left./ \mathrm{ml}\right)$ (formulación líquida).

Se tuvo en cuenta la evaluación del potencial del biofertilizante con los parámetros de altura del tallo, número de hojas, color de las hojas, tomado cada 15 días, y los datos de peso fresco total (g), peso seco total (g), longitud raíz, número de nódulos y color de nódulos, registrado cada 30 días (Cruz, 2009). Así mismo, se establecieron criterios para clasificar la nodulación (baja, media y alta), teniendo en cuenta el mayor número de nódulos/raíz presentado (Contreras et al., 2007). Los bioensayos fueron corroborados estadísticamente en el programa $R$ Project ${ }^{\circledR}$, con el empleo de un diseño completamente aleatorio, los resultados son sometidos al análisis de varianza, utilizando medidas de tratamientos comparadas según la prueba Tukey al $5 \%$.

Fase III: A partir del trabajo de los bioensayos se generó una cartilla como aporte a la enseñanza de los procesos biotecnológicos en la escuela, dando a conocer las ventajas de los biofertilizantes, así como las diferencias entre los tratamientos realizados en el trabajo; orientando al docente a acercarse a la biotecnología, desarrollando hábitos de investigación sobre temas tecnocientíficos socialmente relevantes a partir de la búsqueda, selección, análisis y valoración de las diversas informaciones disponibles (Quintero, 2009). También se plantearon competencias científicas de tipo conceptual, procedimental y actitudinal de modo que se pueda evaluar el material de acuerdo a los propósitos planteados, así como a la coherencia, estructura, contenido, forma y precisión, desarrollando habilidades y aptitudes científicas en el contexto del IPN.

Fue delimitada la población de docentes de Biología del IPN, definiendo los contenidos para la cartilla, además de las temáticas y el enfoque. En el contenido del material, se tomó por referencia algunos materiales educativos como los presentados por la fundación Omacha. La cartilla está acompañada de fotografías, esquemas e imágenes que le permiten al docente tener claridad de las ideas expuestas. En la edición del material didáctico se buscó que el diseño estuviera ajustado a las necesidades de aprendizaje de los docentes a quienes va dirigido, facilitando a quienes los reciban adquirir nuevos conocimientos, habilidades, actitudes, y organizar el material en términos de aprendizaje (Sagá, Guardia, Mas, Girona, 2005), de acuerdo con el modelo pedagógico del colegio que es el constructivismo y el énfasis de múltiples desarrollos.

- La cartilla comprende:

- Trabajos prácticos

- Argumentación

- Motivación para participar en proyectos científicos

- Visita a instituciones como Corpoica y Universidad Nacional de Colombia (Facultad de Agronomía)

- Participación en foros y debates

Con los elementos citados se diseñó la cartilla en el programa InDesign ${ }^{\oplus}$ teniendo en cuenta los elementos pedagógicos, didácticos y biológicos, para fortalecer el proceso de enseñanza de biología y llevar temas de la biotecnología que no son conocidos en la escuela como propuesta para reducir los fertilizantes químicos.

Fase IV: La cartilla fue validada por docentes de biología, en este proceso participaron diez docentes conformados por cinco del IPN y cinco de la Universidad Pedagógica, seleccionados por sus conocimientos en temas de pedagogía, biotecnología, ecología y educación ambiental. Los cuestionarios y sugerencias a la cartilla se tuvieron en cuenta para realizar correcciones que permitieran retroalimentar el material didáctico de acuerdo con las competencias, enriqueciendo así el trabajo.

Finalmente, se realizaron análisis de los datos obtenidos mediante tabulación y graficación de los aspectos de presentación, contenido y metodología de los cuestionarios, con las correspondientes correcciones. También un análisis de contenido descriptivo a las preguntas abiertas a partir de categorización del texto (Piñuel, 2002).

\section{Resultados y discusiones}

Con el propósito de aproximar la enseñanza de la biotecnología de forma práctica en la granja integral del IPN, se diseñó una cartilla con la temática sobre el uso de buenas prácticas en la granja y elaboración de un biofertilizante a partir de la bacteria Rhizobium sp para cultivo de plantas de Phaseolus vulgaris, haciendo uso de los resultados biológicos de la elaboración del biofertlizante que fueron un aporte importante para mostrar en el material didáctico las razones para la reducción de fertilizantes químicos.

Teniendo en cuenta esto, se puede pensar que enseñar biotecnología en el Instituto Pedagógico Nacional no es una actividad exclusiva para el énfasis en los grados $10{ }^{\circ}$ y $11 .^{\circ}$, sino también puede ser enseñado en diferentes 
niveles para responder a las temáticas de la ciencia y la tecnología, educando ciudadanos que puedan interesarse en estos asuntos y trabajar en áreas afines, en proyectos de aula y de interés con miras al futuro.

Para orientar el desarrollo del material, evaluar las temáticas y desarrollar habilidades con su contenido, se formularon competencias científicas que se ajustaron al contexto de enseñanza y a la granja de la institución con el fin de desarrollar las actividades propuestas donde se indica a qué tipo de competencia se hizo referencia:

Competencia conceptual: Comprender la relación entre la biotecnología y la ecología en la enseñanza de la interacción Rhizobium sp-Phaseolus vulgaris (frijol común) deteriorada por el uso de fertilizantes químicos.

- Competencia procedimental: Identificar las principales características de la interacción Rhizobium sp y Phaseolus vulgaris a nivel de laboratorio y en los agroecosistemas, por medio de actividades prácticas especialmente en la granja integral del IPN.

- Competencia procedimental: Comparar los efectos de los fertilizantes químicos con el biofertilizante de la bacteria Rhizobium sp en Phaseolus vulgaris con actividades prácticas.

- Competencia actitudinal: Reconocer los efectos de los daños ecológicos que generan los fertilizantes químicos en la relación simbiótica de Rhizobium sp con Phaseolus vulgaris como un aporte para la comprensión de las implicaciones sociales de la ciencia.

Así pues la cartilla contiene los siguientes aspectos:

- Competencias.

- Actividades.

- Preguntas orientadoras.

- Espacio para notas.

- Papel de la enseñanza.

Por consiguiente, para desarrollar las competencias, el trabajo comienza en el laboratorio de biotecnología donde se activaron 12 cepas conservadas de Rhizobium en el medio ELMARC. Algunos géneros son similares a las bacterias en estudio, por lo cual se descarta la presencia de bacterias del género Bradyrhizobium, porque las bacterias fueron de crecimiento rápido, presentaron acidez y turbidez en el medio (figura 1); y de Agrobacterium, debido a que las bacterias no absorben el rojo congo (figura 2). Las características de las bacterias asociadas con el género fueron: borde liso, consistencia mucosa, elevación convexa y coloración blanquecina en el 66,6\% de las cepas en estudio.
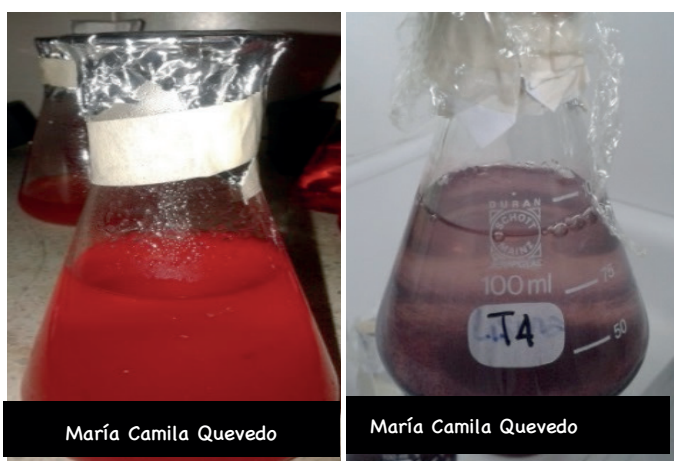

Figura 1. Medio líquido ELMARC. Izq. Medio sin inocular. Der. Medio líquido con Rhizobium sp. Foto tomada por la autora

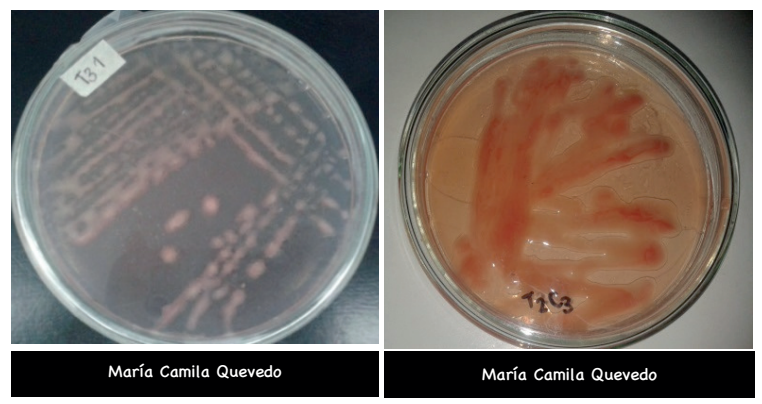

Figura 2. Medios de cultivo ELMARC, sólido izq. Medio de cultivo después de 3-5 días, las colonias presentan mucilago, coloración blanquecina, forma irregular, elevación convexa, borde liso y sin absorción del rojo congo der. Colonias después de 8 días de crecimiento por la absorción del rojo congo. Foto tomada por la autora.

Las cepas se encontraban contaminadas, pero solo aquellas que presentaban morfología bacilar y con coloración mixta de la tinción de Gram se les realiza reaislamiento y purificación de cepas en medios EMB, las colonias aisladas fueron incoloras con un tenue brillo fluorescente que permitieron identificar la ausencia de lactosa en el medio que se diferencia de Agrobacterium sp, que la produce (Cuadrado, Rubio y Santos, 2009), además este medio solo permite crecimiento de bacterias Gram negativas, confirmadas de nuevo con tinción de Gram (figura 3). En las pruebas bioquímicas se reveló el metabolismo celular de Rhizobium, debido a que la prueba TSI corrobora que no fermentan lactosa, produce gas y asimila fuentes de carbono como la glucosa en algunas cepas. Todas las bacterias en estudio resultan positivas para el uso de la catalasa, también en la prueba sım se identifica la presencia de movilidad, sin producción de sulfuro o de indol. Otra característica importante es el citrato, que aportó al trabajo del cepario, ya que solo se había encontrado bacterias Gram negativas en el trabajo de Roa (2000). Sin embargo, en esta misma investigación se afirma que Rhizobium sp es variable para el uso del citrato (Valdez y Martínez, 1986; citado por Roa, 2000). Así mismo, son ácido productoras de acuerdo con los resultados de los medios YMA + azul de bromotimol y McConkey, que indican la presencia de Rhizobium sp y no de Bradyrhizobium, alcalino $\mathrm{y}$ de crecimiento lento. 


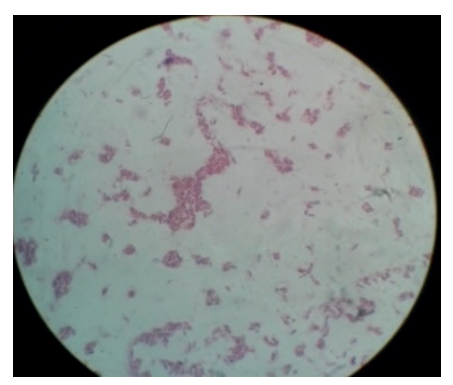

María Camila Quevedo

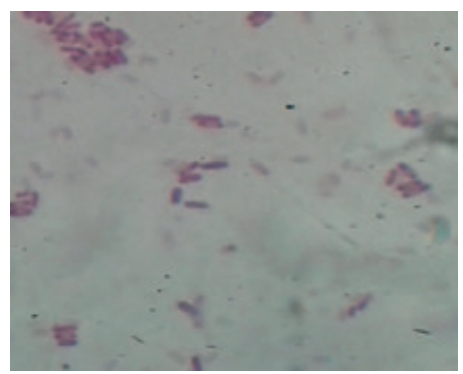

Figura 3. Tinción de Gram de Rhizobium. Observación microscópica cepas 1-7 y 11. Bacilos Gram negativos. Aumento 100 X. Foto tomado por la autora

Por la importancia de las pruebas bioquímicas para la determinación del género, se hace uso de estas para incluirlas en el material didáctico de forma que el maestro pueda encontrar los diferentes medios utilizados para el estudio y aislamiento de Rhizobium y su posterior elaboración del biofertilizante.

Para las pruebas fisicoquímicas del suelo, entre los elementos más comunes para el cultivo del frijol se encontró un $\mathrm{pH}$ de 6,0 adecuado para la siembra del frijol (Arias, Rengifo y Jaramillo, 2007), también la materia orgánica con un valor medio del $5 \%$, generando suelos bien estructurados y estables, contribuyendo en gran parte con la capacidad de intercambio catiónico. Las propiedades granulométricas miden el tamaño de las partículas que según el triángulo textural indican que están entre franco arcillosos y franco limosos, con amplio rango de siembra y adecuado para sembrar frijol. Los niveles de nitrógeno equivalen a $0,93 \%$, que revelan gran cantidad de este elemento en el suelo, pero no puede ser utilizado elementalmente y tiene que obtenerse en forma de nitrato con ayuda de bacterias fijadoras de nitrógeno (Arias et al., 2007; Martínez y Carmona, 2007). Estos análisis muestran que los suelos de climas fríos y medios donde se cultiva el frijol en Colombia son muy variables por la habilidad de adaptarse a una gran cantidad de condiciones de suelo y topografía (Ríos, 2002; citado por Arias et al., 2007), por lo que algunas carencias o excesos de los nutrientes pueden ser contrarrestados con el uso de fertilizantes $y / 0$ biofertilizantes.
Para este caso, en el material didáctico se consideró el suelo como sistema vivo, con biodiversidad, ciclos, microambientes y metabolismo propio, pero para las actividades humanas solo es importante en términos de productividad. Por esto, se propuso que con los agr ecosistemas, el conocimiento agrícola, ambiental y ecológico se puede trabajar en la granja escolar sin hacer uso de agroquímicos que vuelven los suelos infértiles, propensos al ataque de plagas y reducen la biodiversidad; haciendo uso de un personaje quien compaña los aspectos sociales en la cartilla (figura 4). El material contiene letra y uso de colores llamativos para motivar al lector, además de hacer uso de fotografías de la investigación biológica y de preguntas orientadoras que acompañan cada una de las temáticas.

Por tanto, teniendo en cuenta la metodología de las pruebas fisicoquímicas, se plantea una actividad para analizar el suelo haciendo uso de la granja y los laboratorios para determinar el $\mathrm{pH}$ con soluciones caseras, realizar perfil de vegetación, determinar los componentes del suelo, pruebas preliminares de su textura, color y composición llenando una botella con suelo para diferenciar arenas, limos y arcillas, como también la actividad microbiana, teniendo en cuenta la competencia de tipo procedimental.
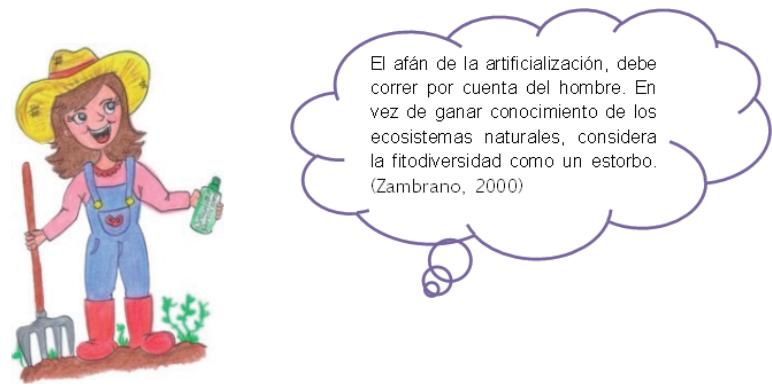

Figura 4. Granjera, personaje de la cartilla didáctica. Explicación de la granja acerca de un asunto social de la ciencia como lo es la artificialización.

Las ilustraciones fueron diseñadas para especificar temas como las etapas del frijol en el desarrollo de la simbiosis, facilitando la comprensión y permitiendo que en el momento de la siembra en la granja, los maestros y sus estudiantes puedan relacionar las estructuras, diferenciarlas, observar, tomar datos y hacer seguimiento al ciclo de vida.

Por otro lado, para la preparación del biofertilizante se elaboró con referencia al patrón de McFarland con tal de predecir el número de bacterias en las formulaciones del mismo. En la formulación solida se evaluó con diluciones seriadas comparándolas a la escala con una concentración 
de 6,0 $\times 10^{8} \mathrm{UFC} / \mathrm{ml}$, (tubo 1 McFarland) y en la formulación líquida $1,5 \times 10^{9} \mathrm{UFC} / \mathrm{ml}$ (tubo $5 \mathrm{McFarland}$ ) (figura 5).

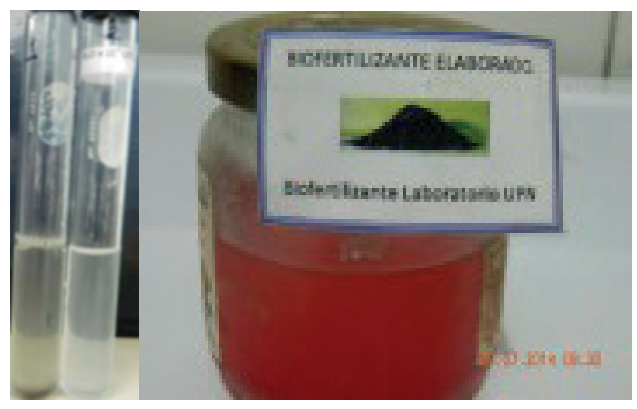

Figura 5. Formulaciones de biofertilizante. Izq. Formulación solida de dilución seriada comparada con el tubo 1 de la escala McFarland. Der. Formulación líquida del biofertilizante con concentración de 1,5× $109 \mathrm{UFC} / \mathrm{ml}$.

Foto tomada por la autora.
Las formulaciones de biofertilizantes y los demás tratamientos fueron evaluadas en los bioensayos de acuerdo a parámetros de altura del tallo, número de hojas trifoliadas, número de nódulos y color. De acuerdo con el análisis estadístico los bioferfertilizantes tuvieron una similaridad del $98 \%$ con Crecilizer ( $\mathrm{F}<0,9803757$ ), ya que el suministro adicional de nutrientes favoreció la longitud de las raíces y efectivamente el tratamiento del agua destilada resulto negativo (gráfica 1 ). De la misma forma, para las hojas, de nuevo los biofertilizantes presentan resultados positivos en cuanto al color y cantidad, a pesar de que el tratamiento químico se acerque a estos datos, las hojas presentaron coloración amarilla y lunares en los tratamientos 1 y 2 (figura 6) debido a la disminución de clorofila, fotosíntesis y dificultad en la actividad enzimática (Fago, 2007), por la falta de nitrógeno y de otros posibles nutrientes como el magnesio.

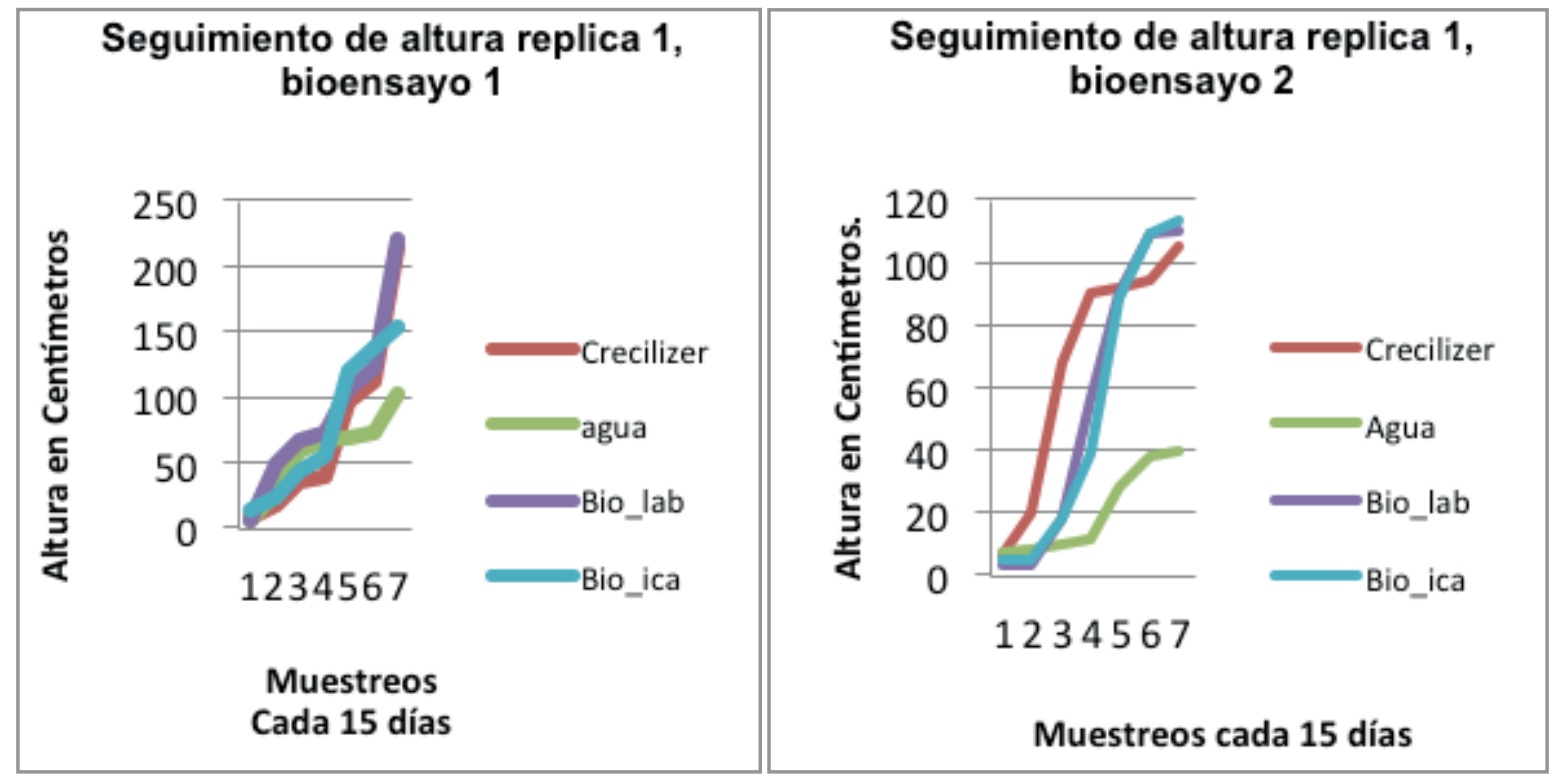

Gráfica 1. Seguimiento del crecimiento de una semilla de fríjol. Izq. Bioensayo 1. Der. Bioensayo 2
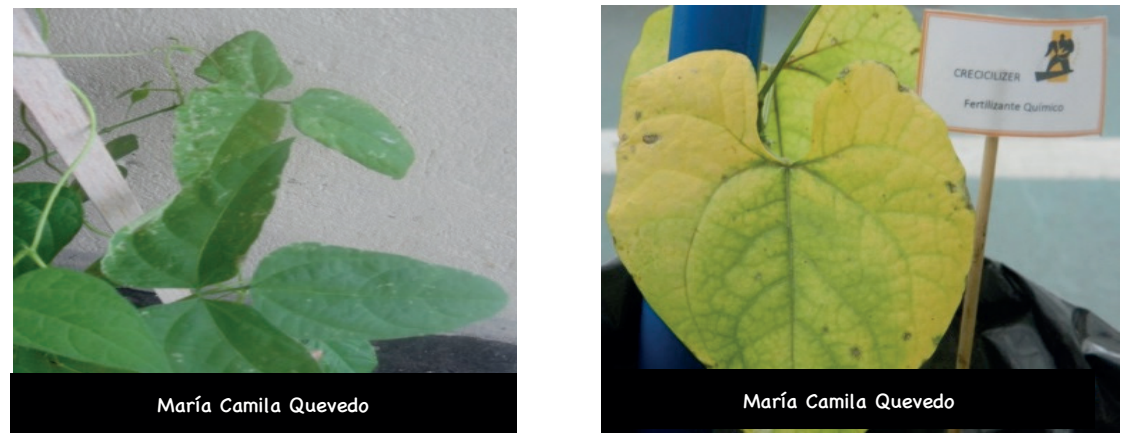

Figura 6. Deficiencia en el nitrógeno con el uso de fertilizante químico. Izq. Manchas presentes en hojas viejas. Der. Hojas amarillas por falta de nitrógeno. Foto tomada por la autora. 
Aun así, los datos obtenidos de peso verde y seco de acuerdo con los análisis de Tukey muestran que ninguno de los tratamientos presentan diferencias significativas, la similaridad entre estos demostró que Crecilizer presenta mayor retención de humedad en tallo y hojas, sin efectos negativos para el abastecimiento de agua; mientas que los tratamientos de los biofertilizantes aseguran la infectividad por parte de Rhizobium, permitiendo buena absorción de nutrientes y la interacción entre el hospedante y simbionte (Soriano y González, 2012). También puede corroborase con el peso seco, ya que Rhizobium puede producir acc (aminociclopropano carboxilato) diaminasa; compuesto que reduce el nivel de etileno en las raíces, incrementando de esta manera la longitud y su crecimiento (Crespo y Julio, 2012); como la cantidad de fósforo del suelo que aumenta el peso seco de los nódulos estimula la cantidad y porcentaje de FBN (Contreras et al., 2007); el peso seco dependerá del tiempo de contacto de la solución de nutrientes con las raíces, el número de extracciones de agua del suelo, crecimiento y desarrollo.

De esta manera, los datos anteriormente expuestos dieron a conocer que los fertilizantes químicos no tendrían efectos adversos en el frijol. Sin embargo, en la evaluación de la nodulación (gráfica 2), se clasificó la nodulación alta con el biofertilizante de laboratorio con más de 300 nódulos formados, infectivos porque Rhizobium se adhiere a la planta y efectivos al ejercer la simbiosis, al observarse la coloración rosada que indica la presencia de leghemoglobina (Matos, Ormeño y Zúñiga, 2001; citado por Crespo y Julio, 2012). La nodulación media ocurrió en el biofertilizante ICA debido a que los productos comerciales también presentan ventajas para la producción agrícola; la nodulación baja en el agua destilada pues los pocos nódulos encontrados se deben a la cercanía de la planta al tratamiento 3 donde ocurre una posible transferencia lateral de marcadores cromosómicos de Rhizobium; y la nodulación nula en Crecilizer, con pérdida de filtración del suelo y deterioro en las raíces por la presencia de altas concentraciones del fertilizante que inhibe la nodulación, disminuyendo la formación de pelos capilares y adhesión de bacterias a sus paredes.

La cantidad de nódulos presentados en el biofertilizante del laboratorio como la respuesta positiva a los parámetros en estudio indican que los tubos del cepario de la Universidad Pedagógica Nacional tienen capacidad biofertilizante, lo que demuestra compatibilidad entre la planta y los rizobios (Cruz, 2009). Estos resultados indican que puede hacerse una disminución de productos químicos, sustituyéndolos por biofertilizantes que tienen respuestas positivas teniendo en cuenta las variables ecológicas; reducción de costos, conservación del suelo con su biodiversidad, menor dependencia a insumos externos y productividad; $y$ culturales (prácticas agroecológicas que incluyan al ser humano en las relaciones entre las especies, haciendo uso de agroecosistemas como un primer avance al enfoque ecológico).

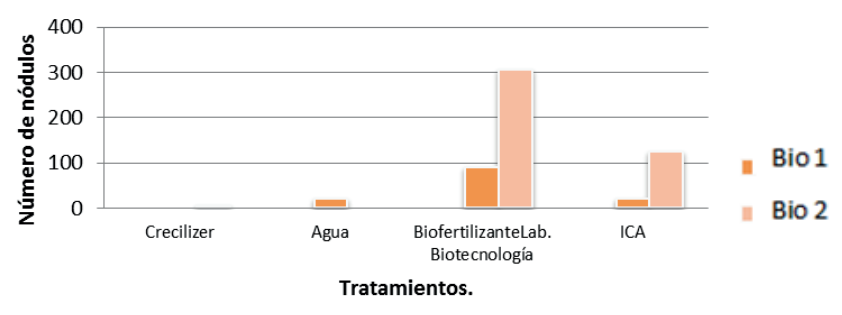

Gráfica 2. Evaluación total de la nodulación

De esta manera se plantea como actividad práctica trabajar en los laboratorios para la producción del biofertilizante con dos metodologías que pueden desarrollarse en el contexto de la institución, la primera con la obtención de Rhizobium sp tomando nódulos de frijol (figura 7) y la segunda llevando a cabo la misma que se expuso anteriormente con evidencias fotográficas que apoyan cada uno de los pasos. Con esto, el docente y el estudiante puede corroborar lo aprendido, observar en campo la FBN y comparar los tratamientos. Por tanto, los trabajos prácticos constituyen actividades de aprendizaje características de las ciencias experimentales, que ofrecen la posibilidad de comprender temas complejos y abstractos, permitir el desarrollo de la capacidad de investigación, apreciación de la ciencia e identificar las ideas equivocadas.

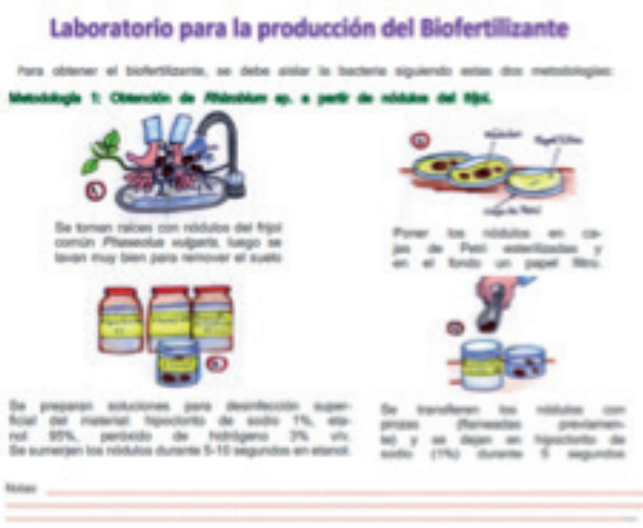

Figura 7. Laboratorio para la producción del biofertilizante. Apartado de la cartilla con el laboratorio de producción del biofertilizante tomando nódulos de leguminosas.

Con esto, el docente puede actuar también como facilitador para buscar motivación de los estudiantes a partir de la interacción dialógica y el trabajo colaborativo como estrategia didáctica (Velasco y Mosquera, 2007). Del mismo modo, en estas actividades se tiene en cuenta 
la resolución de problemas, la cual es importante para la educación en general, en especial para la enseñanza de la ciencia y tecnología al contribuir al aprendizaje de los contenidos de manera práctica, generar una aproximación actitudinal y conceptual a la naturaleza de la ciencia, fortalecer el pensamiento crítico y reflexivo y ayudar a la apropiación del trabajo en comunidades académicas (Vidal, 2006).

En efecto, se presentaron también las ventajas, desventajas, implicaciones sociales, ambientales y ecológicas, una noticia del contexto colombiano del uso de fertilizantes químicos con una investigación de la Universidad Nacional de Colombia. Y se hace una reflexión final del papel de la enseñanza desde la perspectiva CTSA, dando prioridad a los contenidos actitudinales relacionados con la intervención de estos temas en la sociedad.

Estos resultados biológicos fueron importantes para mostrar los hallazgos encontrados en los bioensayos y los efectos inhibidores de los agroquímicos, lo que permitió que diferentes estudiantes y maestros encuentren en el material las razones para reducir el uso de estos y optar por productos como los biofertilizantes, contextualizó de esta manera la escuela con todo su entorno social e involucró estos aspectos para ayudar a que desde la clase de Biología se puedan tomar decisiones razonadas sobre problemas sociales (Quintero, 2009).

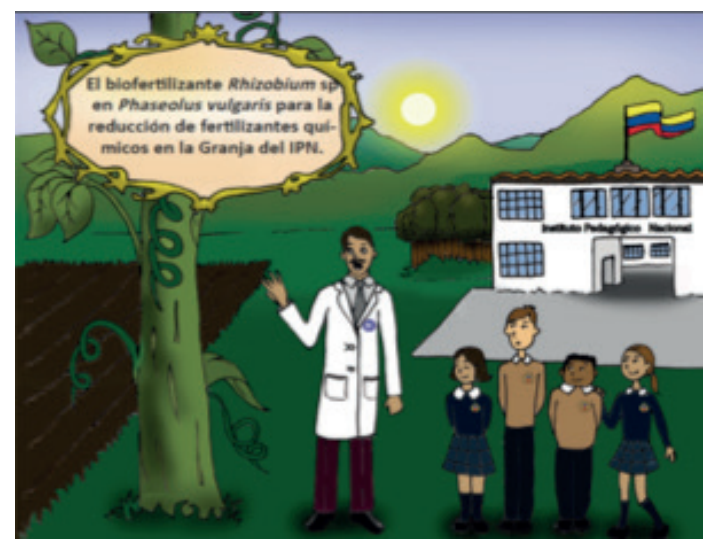

Figura 8. Carátula de la cartilla. Alusión al IPN, la granja, el fríjol y la comunidad educativa

Así también, el aporte generado con la cartilla (figura 8) contiene bases pedagógicas y didácticas, lo que permite que el docente actúe como investigadory participe del desarrollo del material que ofrece los siguientes elementos:

- Título que tiene en cuenta el contexto del Instituto Pedagógico Nacional.

- Competencias científicas.

- Temáticas abordadas desde el método deductivo (general a lo particular).
- Preguntas orientadoras por cada sección.

- Apartado de notas para que el docente haga registros de las clases o de las temáticas de la cartilla (está ubicado en la hoja de inicio de cada tema).

- Figuras acordes con la temática, ya sean tomadas de documentos vía web o ilustraciones dibujadas solo con el fin de vincularlas con los temas explicados (realizadas por un ilustrador); y material visual de apoyo.

- Esquemas adaptados acerca de las explicaciones del tema.

- Explicaciones importantes resaltadas en cuadros de color morado para subrayar ideas fundamentales a lo largo de los conceptos.

- Ilustración de una granjera como personaje que explica sobre temas sociales de la ciencia en relación con uso de los fertilizantes.

- Actividades en campo estandarizadas y complementadas en la cartilla.

- Recomendación de páginas de Internet que ayuden a profundizar el tema.

- Uso de fotografías de la investigación biológica como apoyo a la lectura de los temas y actividades.

- Recuadros explicativos y mapa geográfico con los lugares del cultivo del frijol, historia e importancia.

- Características taxonómicas para identificar el género Rhizobium sp y diferenciarlos de otros géneros.

- Actividades de argumentación y análisis, una de estas tomada de una guía didáctica, "Importancia de Rhizobium en crecimiento y fijación nitrógeno de la planta de Phaseolus vulgaris", presentada por la autora de este texto en el 2013. La otra actividad es una propuesta a partir de un una lectura base: "Obtención y manejo de biofertilizantes como insumo indispensable de la agricultura sostenible" de Álvarez y Martínez (2008).

- Laboratorios para la producción de biofertilizantes a partir de nódulos y con cepas conservadas en congelación.

- Noticias de actualidad sobre el uso de fertilizantes químicos en Colombia.

- Propuesta de salidas pedagógicas a Corpoica y la Universidad Nacional de Colombia.

- Difusión de la información en carteleras acerca de lo aprendido por parte de los estudiantes, con el propósito agregado de abrir espacios en el semillero de investigación, en las clases de Biología y promover contactos con líderes ambientales.

- Propiciar el uso de los laboratorios del IPN, ya que este espacio puede ser aprovechado por maestros y estudiantes para desarrollar la producción del biofertilizante.

- Vocabulario.

- Bibliografía. 
Además, para comprender la complejidad de la simbiosis, se dividió en diferentes aspectos: una explicación de las características de las especies por separado, y una observación del proceso de simbiosis paso a paso, desde la adhesión hasta la transformación de la bacteria y fijación de nitrógeno. Como la bioquímica y genética de la nodulación que se propone está de acuerdo con los estándares básicos de $8 .^{\circ}$ y $9 .^{\circ}$ grado, puede enseñarse en los diferentes grados de acuerdo con la complejidad del tema, para facilitar la comprensión y ampliar lo que sucede al interior de cada nódulo hasta llegar al ciclo de Krebs.

La cartilla incluye, asimismo, un taller de aula con una situación problema, para motivar trabajo en clase que ayude a interpretar situaciones y buscar soluciones. Hay también otra actividad con una lectura sobre el manejo de biofertilizantes y preguntas para un estudio de caso, que pueden ser discutidas tanto en el semillero de investigación como en el aula, y buscan promover en los estudiantes la capacidad de interpretar artículos, organizar ideas y promover la argumentación. Estas actividades fueron planteadas para desarrollar la competencia de tipo actitudinal, enfocada en reconocer los efectos de los daños ecológicos que generan los fertilizantes en la relación simbiótica como aporte a la comprensión de las implicaciones sociales de la ciencia, ya que el maestro puede hacer énfasis en la actitud crítica ante el uso de la tecnología y la repercusión en el ambiente (Vidal, 2006).

De acuerdo con esto, para las competencias, los docentes (D) indican que es necesario fortalecerlas no centrándose en el contenido, sino en competencias que permitan realizarse actividades que estén en el material y sean explicitas para los estudiantes (D4) y centrarse en la competencia actitudinal (D6); para así desarrollar habilidades y actitudes científicas que fomenten la exploración de la simbiosis, y ayuden a que el estudiante construya aprendizaje, amplíe su curiosidad, persistencia, disposición para trabajar en equipo y una valoración crítica de los descubrimientos científicos (Ministerio de Educación Nacional, MEN, 2006).

Adicionalmente, permitió evaluar el material de acuerdo con el contenido conceptual, motivacional y las habilidades que se pueden desarrollar, teniendo en cuenta que las competencias se encuentran relacionadas con las actividades y contenido propuesto en el material (anexo 1). En cuanto a la presentación de la cartilla (gráfica 3), el $60 \%$ de los docentes estuvieron totalmente de acuerdo con el diseño de la carátula, el $50 \%$, con la distribución de las figuras y el color, que se trata bien en las páginas, y también el $50 \%$, con el diseño de la cartilla en relación con el contenido propuesto, lo que indica que la presentación de la cartilla es adecuada y está presentada de forma llamativa. Además, en el análisis de contenido algunos docentes indicaron que los textos son muy densos, letra pequeña en algunos momentos que dificulta comprensión de tema (D5). Revisar las imágenes, algunas páginas cargadas y textos (D7) o que Es visualmente atractivo y hay orden conceptual (D3)".

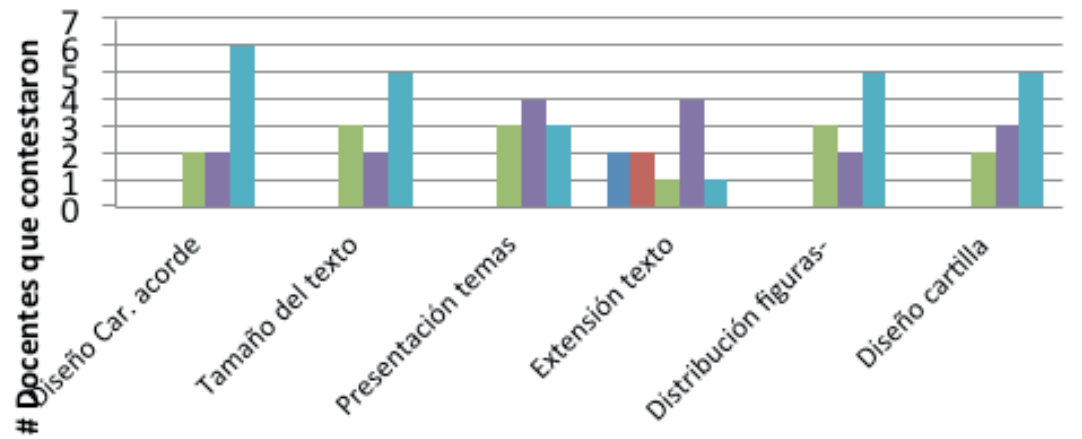

- Total. desacuerdo

- Desacuerdo

- Parcialmente acuerdo

- Acuerdo

- Total. acuerdo

Aspectos

Gráfica 3. Aspectos de presentación validados en la cartilla 
En lo que atañe a los aspectos de contenido (gráfica 4), el $70 \%$ de los docentes está en total acuerdo con los conceptos abordados, el $50 \%$, con que la secuencia es coherente con los contenidos, el $30 \%$, con que las imágenes facilitan la comprensión, y el $50 \%$, con que las temáticas motivan al lector. No obstante, un $10 \%$ de los docentes están en desacuerdo con que las imágenes y figuras facilitan la comprensión del contenido conceptual. Ante esto, en las preguntas, abiertas los docentes expresaron que puede usarse en diferentes grados, teniendo en cuenta la profundidad y surge como herramienta para el trabajo en la Granja (D1). No se centre tan solo en contenidos, es fundamental las competencias, muy difícilmente se notan en el material (D3). Permite que el maestro se apropie de las temáticas y busque nuevas posibilidades de trabajar cosas prácticas (D5). Es clara la secuencia y contiene actividades de refuerzo para estudiantes (D6).

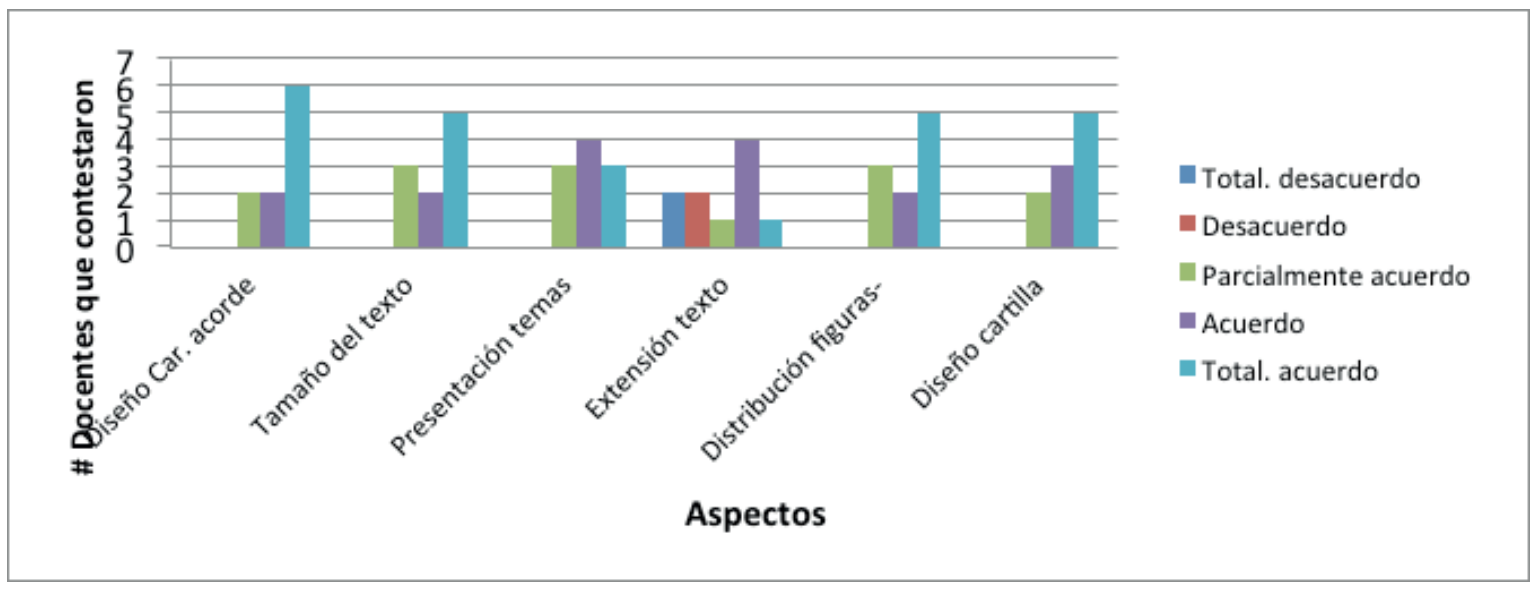

Gráfica 4. Validación del contenido del material didáctico

En cuanto a lo metodológico (gráfica 5), el $80 \%$ de los docentes mostraron total acuerdo con que las actividades prácticas se relacionan con las temáticas y son apropiadas para comprender el tema, un $80 \%$, con que la estructura y las temáticas invitan a que el lector realice las actividades prácticas; lo que indica que en el aspecto metodológico la cartilla es muy pertinente. Entre los aspectos que requieren ser ajustados está la organización de las temáticas y la estructura que invite a que el docente realice la lectura. Con esto fue importante tener en cuenta aspectos de practicidad no claros dentro de la cartilla y expresados por los docentes al nombra que falto guía para el seguimiento de Rhizobium (D4). Proponer no solo el medio de cultivo ELMARC, no en todos los colegios hay los reactivos, se puede un medio menos complejo (D10). Podrían generarse actividades en torno a estudios de caso en vez de preguntas orientadoras (D1).

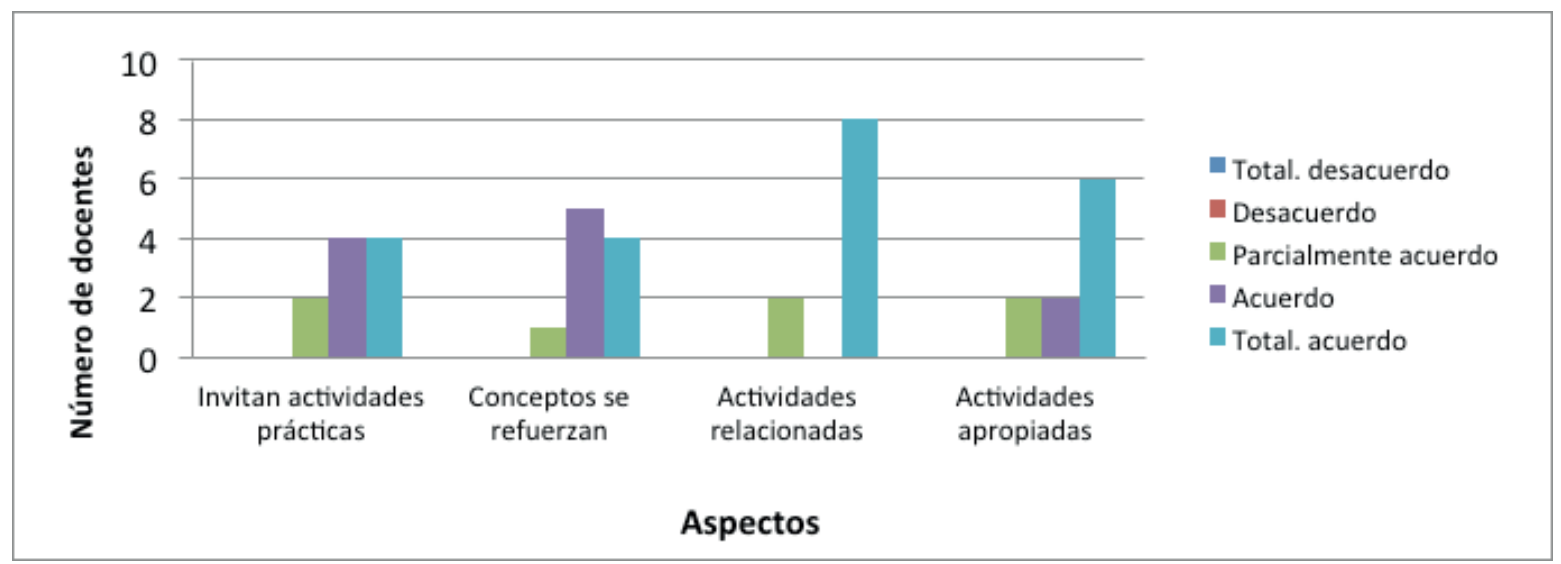

Gráfica 5. Aspectos metodológicos de la cartilla validada por los docentes 
Entonces, la cartilla es una estrategia que puede apoyar la clase de Biología con los trabajos prácticos, pues lleva al estudiante a plantearse preguntas desde su contexto de aula, ciudad y país, de acuerdo a los productos convencionales de síntesis química y los biotecnológicos, con situaciones que le permitirán fortalecer los conceptos biológicos y prácticos, como son las interacciones simbióticas planta-bacteria. En este sentido, la enseñanza de la biotecnología puede ser una alternativa para reflexionar sobre el proceso que realiza el ser humano desconociendo en algunas prácticas agrícolas los sistemas biológicos.

En los ajustes se tuvo en cuenta el fortalecimiento de las competencias más relacionadas con las actividades. Se platearon otras donde el docente puede indicarle a sus estudiantes los lugares de siembra del frijol, las características del relieve, el periodo de siembra usando el mapa geográfico de la institución con algunas preguntas para identificar la calidad del suelo, las fuentes hídricas para el cultivo, las variedades del frijol y su importancia económica, social y cultural en Colombia (figura 9).

Con la cartilla educativa, se utilizaron diferentes estrategias didácticas, como el trabajo en campo, salidas pedagógicas, actividades de análisis, el lápiz y el papel, trabajo colaborativo, los laboratorios, la resolución de problemas y el desarrollo discursivo; estrategias que permitieron pensar el papel de la enseñanza desde la práctica pedagógica que se ha nutrido con el papel y el rol del maestro como formador de sujetos que participan en la sociedad. Además, la formación de esta profesión ha estado marcada con experiencias significativas, el aprendizaje de otros maestros en ejercicio, por ejemplo, lo que ha llevado a plantear actividades en torno a la enseñanza de la biología, y ha permitido enriquecer la labor realizada por otros docentes mediante alternativas que se pueden trasladar para fortalecer la labor en el IPN con la propuesta del uso de espacios de la institución que son adecuados para trabajar diversas temáticas.

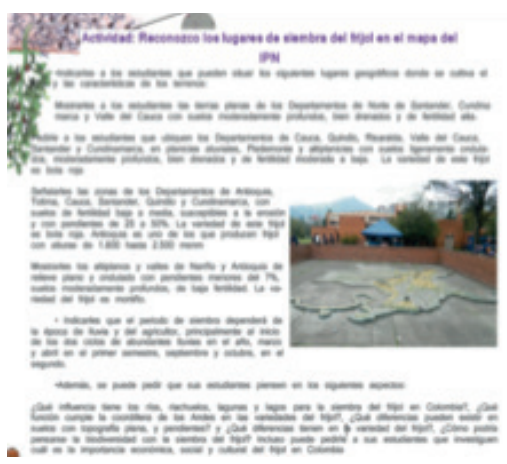

Figura 9. Actividad de la cartilla. Reconocimiento de lugares geográficos de la siembra del fríjol en Colombia, haciendo uso del mapa geográfico del IPN.

\section{Conclusiones}

La cartilla didáctica El biofertilizante Rhizobium sp en Phaseolus vulgaris para la reducción de fertilizantes químicos en la granja del IPN es una propuesta integradora de elementos biológicos y pedagógicos que recogen un trabajo investigativo que puede ser llevado a un contexto escolar para ser trabajado con los docentes en temáticas transversales que complementan los contenidos de la CTSA y contextualizar a la escuela en los temas socialmente relevantes que se viven en Colombia y los avances biotecnológicos, dentro de cuyas reflexiones se puede formar personas capaces de actuar y tomar decisiones ciudadanas.

Además, desde el cepario de la Universidad Pedagógica se pueden estudiar microorganismos con el fin de planear diferentes estrategias didácticas para el conocimiento biológico o de temas específicos como las interacciones. Con la cartilla, el maestro puede percibir la ciencia escolar como el camino de formación para los próximos estudiantes en carreras científicas o áreas afines, o ayudarle al estudiante a entender su contexto de forma significativa desde el lenguaje y las competencias científicas, ya que el conocimiento de esta investigación puede llegar al escenario escolar y orientar el trabajo en diferentes espacios de la institución como el semillero de investigación, líderes ambientales, énfasis de biotecnología, el aula, y desarrollando algunas actividades como visitas a centros de investigación, estudios de caso, laboratorios y proyectos de los estudiantes.

Por lo tanto, este material cumple como estrategia didáctica con el objetivo y la metodología, las actividades pueden desarrollarse en diferentes niveles escolares y presenta aportes para la enseñanza de la simbiosis, procesos biotecnológicos y reducción de fertilizantes químicos, debido a que el papel del maestro es fundamental en la enseñanza de los conceptos biológicos, pero más aún es clave en la formación de ciudadanos frente al uso de la tecnología y de los procesos de globalización, y deben ser tenidos en cuenta en el complejo contexto social que se vive en Colombia frente al uso de los recursos y la apreciación al sistema suelo, en este caso, la biología podría ser un gran aporte a los temas ecológicos y ambientales en la escuela, ayudando a fortalecer la investigación que le permita pensar al individuo científicamente. 


\section{Referencias}

Alcaldía Mayor de Bogotá D. C. (2007). Colegios públicos de excelencia para Bogotá. Bogotá: Serie de Cuadernos de Currículo.

Alteri, M., y Nicolls, N. (2004). Una base agroecológica para el diseño de sistemas diversificados de cultivos en el trópico. Manejo Integrado de Plagas y Agroecología, 73, 8-20.

Arias, H., Rengifo, T., y Jaramillo, C. (2007). Buenas prácticas agrícolas (BPA) en la producción de fríjol voluble. Colombia: Corpoica, MANA, FAO.

Baquero, D., y Rojas, L. (2005). Hipermedial una herramienta didáctica para explorar la biofertilización nitrogenada basada en la simbiosis Rhizobium-leguminosa (Tesis de Grado). Universidad Pedagógica Nacional, Bogotá.

Bautista, H., y Valdés, M. (2008). Frankia y la simbiosis actinorrízica. Microbiología, 50(3 y 4).

Cerda, H. (2002). Elementos de la investigación como reconocerlos, diseñarlos y construirlos [4. ${ }^{\text {a }}$ ed.]. Quito: Abya Yala.

Contreras, C., Iriarte, J., y Muñoz, A. (2007). Aislamiento y caracterización Bioquímica, fisiológica y morfológica de géneros Rhizobium y Bradyrhizobium sp asociados a la leguminosa Cajanus Cajan en parcelas agrícolas del Municipio de Sampués. Sincelejo: Universidad de Sucre. Facultad de Educación y Ciencias. Programa de Biología con énfasis en Biotecnología.

Crespo, L., y Julio, A. (2012) Identificación y caracterización de Rhizobium nativo para la producción de biofertilizante en la provincia de Santa Elena (Tesis de Grado). Universidad Estatal Península de Santa Elena, Ecuador. Disponible en: http://www.repositorio.upse.edu.ec:8080/handle/123456789/889

Cruz, M. (2009). Aislamiento y selección de Rhizobium $\mathrm{sp}$, nativos de suelos de Moriella, Michoacán, para frijol (Phaseolus vulgaris). México: Universidad Michoacana de San Nicolás de Hidalgo.

Cuadrado, B., Rubio, G., y Santos, W. (2009). Caracterización de cepas Rhizobium y Bradyrhizobium (con habilidad de nodulación) seleccionados de los cultivos de frijol caupí (Vigna unguiculada) como potenciales binóculos. Rev. Colombiana. Ciencia. Quím. Farm., 38(1), 78-104. Disponible en http://www.revistas.unal.edu. co/index.php/rccquifa/article/view/15432/36602

Fago, X. (2007). Estudio comparativo del proceso de obtención de un aditivo enzimático mediante fermentaciones microbianas sólida y sumergida de Afrechillo de trigo. Valencia: Universidad de Carabobo.

Martínez, Duarte (2007). Estrategia pedagógica y didáctica desde el enfoque ciencia, tecnología sociedad y ambiente, a partir de las fumigaciones con glifosato. Bogotá: Universidad Pedagógica Nacional. Disponible en: file://C:/Users/Maca/
Documents/Universidad/TRABAJO\%20DE\%20 GADO/Documentos\%20pedagogicos/Solbes.PDF

Ministerio de Educación Nacional (MEN) (2006). Estándares básicos de Competencias en Ciencias Naturales y Ciencias Sociales Formar en ciencias: Lo que necesitamos saber y saber hacer, el desafío. Colombia: Ministerio de Educación Nacional República de Colombia.

Piñuel, X. (2002). Epistemología, metodología y técnicas del análisis. España: Universidad Complutense de Madrid. Disponible en: https:// www.ucm.es/data/cont/docs/268-2013-0729-Pinuel_Raigada_AnalisisContenido_2002_ EstudiosSociolinguisticaUVigo.pdf

Quintero, C. (2009). Diseño, experimentación y evaluación de materiales curriculares para la formación en ciencia, tecnología y sociedad. Cali: Universidad Santiago de Cali.

Rivera, D. (2012). Formulación de un prototipo de biofertilizantes con base en Rhizobium sp (Trabajo de grado). Bogotá: Universidad Nacional de Colombia.

Roa, R. (2000). Aislamiento, caracterización y conservación de rhizobios a partir de nódulos de leguminosas de diferentes lugares geográficos de Colombia (Trabajo de grado). Bogotá: Universidad Pedagógica Nacional.

Roa, R. (2011). Didáctica de la biotecnología en la escuela. Bio-grafía, 0(00), 00-00. Disponible en: http://revistas.pedagogica.edu.co/index.php/bio-gafia/article/ view/1560/1502

Roa, R., Chavarro, C., Sandoval, Y. (2008). Formación de profesores de biología a través de la biotecnología. Bogotá: Universidad de la Sabana. Disponible en http://educacionyeducadores.unisabana.edu.co/ index.php/eye/article/view/732/1710

Sanga, A., Guárdia, L., Mas X., y Girona, C. (2005). Los materiales de aprendizaje en contextos educativos virtuales. pautas para el diseño tecno pedagógico. Barcelona: Eureca Media. Disponibledehttp:// books.google.com.co/books?id=98RQgPsO4zgC\&pg=PA30\&dq=artista realiza un boceto antes de crear su obra para el diseño de un material\&hl=es-419\&sa=X\&ei=qthEU66CMYW50AH_j4GYBQ\&ved $=0 C C w Q 6 A E w A A$

Soriano, B., y González, A. (2012). Efecto de la inoculación de Rhizobium etli sobre el crecimiento vegetal de páprika, Capsicum annuum var. Longum, y lechuga, Lactuca sativa. Revista Científica de la Facultad de Ciencias Biológicas, 32(1), 31-103.

Velasco, M., y Mosquera, F. (2007). Estrategias didácticas para el aprendizaje. Disponible en: http://acreditación.udistrital.edu.co/flexibilidad/estrategias_ didacticas_aprendizaje_colaborativo.pdf

Vidal, J. (2006). Manual de la educación. Barcelona: Grupo Océano. 


\section{Anexo 1 \\ Formato de validación del material didáctico: El biofertilizante Rhizobium sp como alternativa para la estimulación de la simbiosis con Phaseolus vulgaris en la granja del IPN}

(Con referencia Pulido y Riveros, 2001 en Amaya, 2012)

Nombre:

Institución:

Cargo:

Fecha:

Este formato hace parte del proceso de validación de la cartilla denominada El biofertilizante Rhizobium sp como alternativa para la estimulación de la simbiosis con Phaseolus vulgaris en la granja del IPN desde una dimensión pedagógica y disciplinar, para verificar las competencias, la temática, organización, diseño y propuesta a partir del eje central de la relación biotecnología-ecología y hacer énfasis en la producción del biofertilizante Rhizobium sp en Phaseolus vulgaris a partir de la reducción del uso de fertilizante químicos que empobrecen los suelos y afectan la simbiosis.

Este diseño de cartilla es el resultado del trabajo de grado para optar al título de Licenciada en Biología y surge con la experiencia en la práctica pedagógica en el Instituto Pedagógico Nacional. Con el propósito de integrar la ciencia, tecnología y sociedad, aproximando al estudiante a los temáticas de la actualidad con el uso de la granja escolar como agroecosistema.

De acuerdo con esta información y con la apreciación de la cartilla, solicitamos responder dentro de la escala de 1-5 siendo 1 totalmente desacuerdo, 2 desacuerdo, 3 parcialmente de acuerdo, 4 acuerdo 5 totalmente de acuerdo.

\begin{tabular}{|c|c|c|c|c|c|}
\hline ASPECTOS & \multicolumn{5}{|c|}{ CALIFICACIÓN } \\
\hline Presentación & 1 & 2 & 3 & 4 & 5 \\
\hline $\begin{array}{l}\text { El diseño de la carátula es acorde } \\
\text { a los contenidos disciplinares y su } \\
\text { presentación es llamativa. }\end{array}$ & & & & & \\
\hline $\begin{array}{l}\text { El tamaño del texto, tipo de letra, } \\
\text { es adecuado para la cartilla. }\end{array}$ & & & & & \\
\hline $\begin{array}{l}\text { La presentación de los temas es } \\
\text { apropiada y agradable. }\end{array}$ & & & & & \\
\hline $\begin{array}{l}\text { La extensión del texto desmotiva } \\
\text { la lectura. }\end{array}$ & & & & & \\
\hline $\begin{array}{l}\text { La distribución de las figuras y el } \\
\text { color es acorde y se distribuyen } \\
\text { bien en las páginas. }\end{array}$ & & & & & \\
\hline $\begin{array}{l}\text { El diseño de la cartilla se relaciona } \\
\text { con el contenido propuesto. }\end{array}$ & & & & & \\
\hline Contenido & & & & & \\
\hline $\begin{array}{l}\text { Los conceptos abordados son } \\
\text { acordes a la temática propuesta. }\end{array}$ & & & & & \\
\hline
\end{tabular}




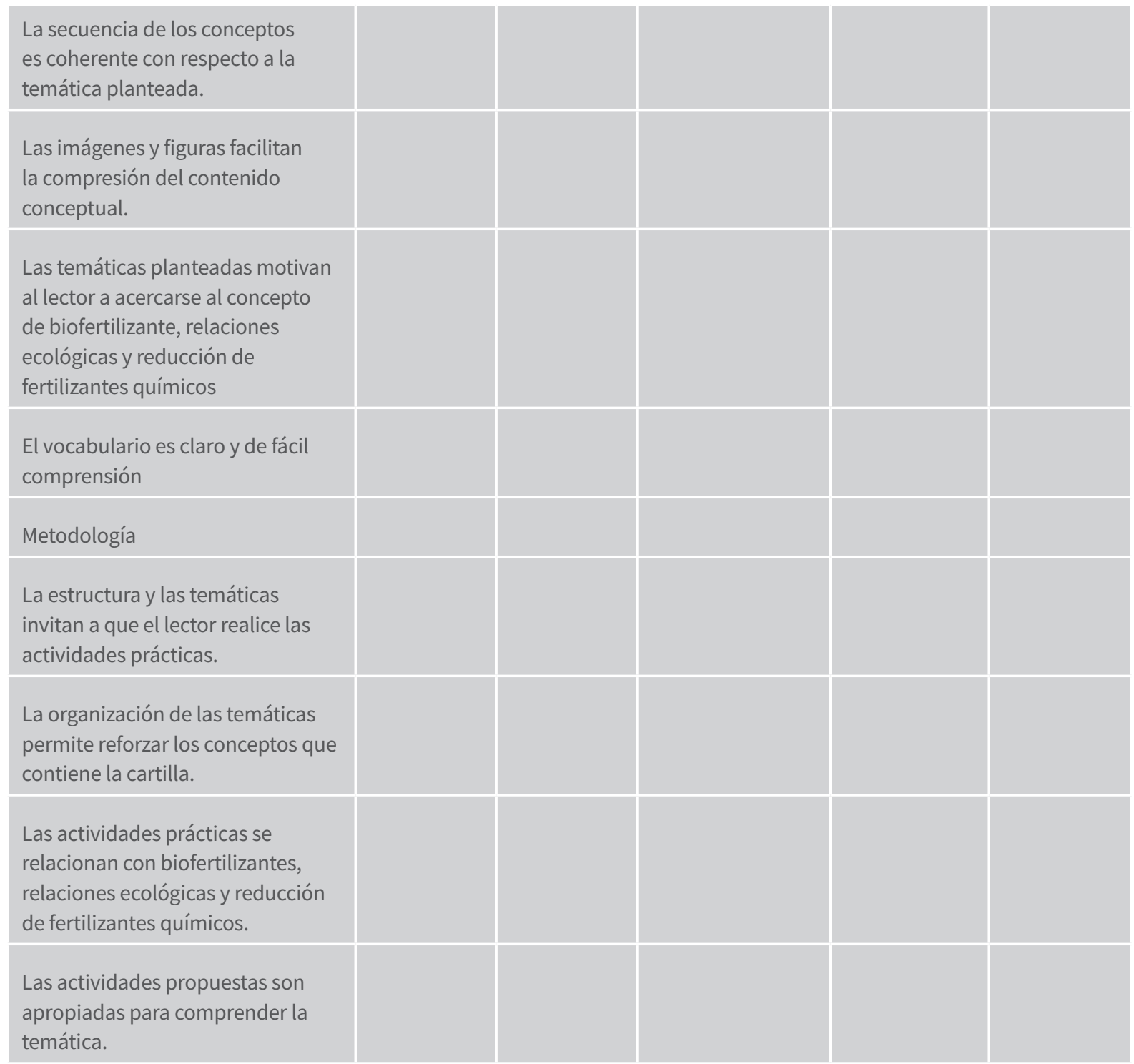

¿Considera que este material didáctico puede ser utilizado en el Instituto Pedagógico Nacional, en el área de Biología para diferentes grados?

¿Encuentra alguna dificultad en la comprensión del tema como lo presenta la cartilla? Si su respuesta es afirmativa, explique.

Observaciones $\mathrm{y} / \mathrm{o}$ aspectos a mejorar. 